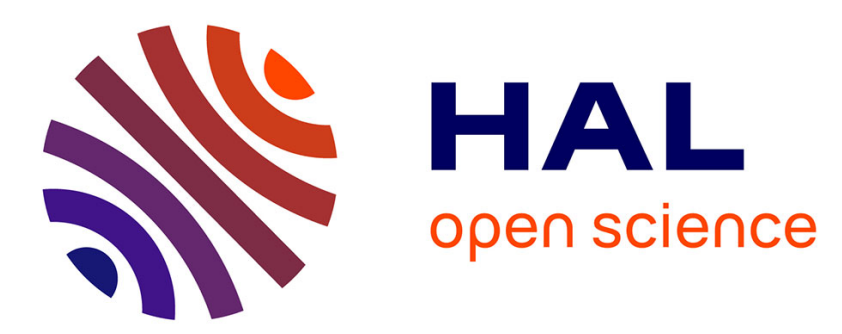

\title{
Wave form of short shock wave reflected from bubble layers in water \\ N. Malykh
}

\section{To cite this version:}

N. Malykh. Wave form of short shock wave reflected from bubble layers in water. Journal de Physique IV Proceedings, 1994, 04 (C5), pp.C5-1121-C5-1124. 10.1051/jp4:19945247 . jpa-00252935

\section{HAL Id: jpa-00252935 https://hal.science/jpa-00252935}

Submitted on 1 Jan 1994

HAL is a multi-disciplinary open access archive for the deposit and dissemination of scientific research documents, whether they are published or not. The documents may come from teaching and research institutions in France or abroad, or from public or private research centers.
L'archive ouverte pluridisciplinaire HAL, est destinée au dépôt et à la diffusion de documents scientifiques de niveau recherche, publiés ou non, émanant des établissements d'enseignement et de recherche français ou étrangers, des laboratoires publics ou privés. 


\title{
Wave form of short shock wave reflected from bubble layers in water
}

\author{
N.V. MALYKH
}

Institute of Thermophysics, Siberian Branch, Russian Academy of Sciences, Lavrentyev Avenue 1, Novosibirsk 630090, Russia

\begin{abstract}
Experimental and theoretical investigation of an influence of the local layer parameters, presence of rigid boundary on the bubble dynamics under the action of strong pressure pulse as well as the formation of reflected signal are reported. It is shown that duration of reflected pulse, its amplitude and presence of an oscillations behing it depend not only on the amplitude and duration of incident pulse, but on the spatial gradient of void fraction and distribution of the bubble radii within the layer. This phenomenon is described within the framework of the model, taking into account a specific variation of void fraction inside the layer as well as the specific bubble dynamics in it.
\end{abstract}

1. Introduction

The formation of reflected wave for the media having internal structure is the result of interactions of secondary waves, which are excited by incident signal on the medium inhomogeneities. If these inhomogeneities are able significantly to change their sizes under the action of pressure pulse, the reflection process is more complicated. Up-to-date it wasn't studied sufficiently. The example of such a process is reflection of the pressure pulse of large amplitude (much more than $0.1 \mathrm{MPa})$ from the water-bubble layers.

Layers consisting of an air bubbles and having the maximum of initial void fraction 0.29 (without rigid boundary) and 0.6 (near-wall case) with the spatial gradients no large than $0.231 / \mathrm{cm}$ were examined experimentally. The initial bubble radii distribution law and the layer thickness also were varied. The maximum amplitude of the incident pulse was $5 \mathrm{MPa}$. Pulses with build-up time, which was much smaller and duration, which was much greater than the typical period of bubble pulsation were examined. The procedure of generation of the bubble layers and the method for measurement of their local structure, using the hot-wire anemometer were briefly given in the study [1].

2. Results and Discussion

The analysis of the experimental data show that structure of reflected signal depends strongly on the amplitude of incident pulse as well as on spatial distribution of the void fraction and bubble sizes. The oscillograms of the signal, reflected from the "free layer with the variation of the incident pulse intensity as well as from the layers haying different spatial gradients of the void fraction at the constant intensity of incident signal are given in Fig. 1. Note that hydrophone, which is placed at some distance in front of the layer registrated the shape of incident pulse at first and only then the structure of the reflected waves is registrated. It is seen, that the decrease of incident 
intensity from 3.5 to $1.5 \mathrm{MPa}$ leads to the increase of reflection factor from 0.28 to 0.66 . ( $F$ ig. $1 \mathrm{a}, \mathrm{b}$ ). Reflection factor is determined as a ratio of the amplitude of the reflected wave to the amplitude of the incident pulse. Analogous phenomena are also observed as the layer void fraction and its spatial gradient decrease ( $F i g . l$ b,c). As intensity of incident pulse increases further a reflection practically disappears. Under our experimental conditions it takes place at $5 \mathrm{MPa}$ approximately. Analysis of high-velocity filming data show that at the layer origin the bubbles compress strongly (up to $0.1 R$ ) under the action of the incident pulse. Wave resistance of the layer increases and reflection decreases respectively. After passage of strong pulse into layer, behind its back front bubbles increase their sizes in a several times due to inertia of associated mass. It leads to the blocking of reflected signal within the layer and almost full passage. The energy of the incident signal decreases, in consequence of that bubbles not only re-emit, but also scatter incident shock. High frequency pulsations in the signal passed into layer is an evidence of this effect ( $F$ ig. 2 ). The typical size of this pulsations is comparable with the distances between individual bubbles. Dscillations behind back front of the reflected pulse contain theinformation about the distribution law of the bubble sizes.

Now consider the reflection from the near-wall layers. Note that the wall used in experiment is not absolutely rigid. It absorbs and then re-emits part of the energy of incident pulse ( $\mathrm{Fig} .3$, a). At the small void fractions and its spatial gradients inside the layer this process strongly affect bubble dynamics. Character of reflection is determined by interaction of the waves re-emitted and scattered by the bubbles and perturbations, generated by the wall ( $F$ ig. $3, b$ ). The first peak in reflected signal and incident pulse have the same polarity. However, its magnitude is essentially less than the one without bubbles. In the presence of the wall it turns out well to obtain values of the void fraction and its spatial gradient, which are higher, than the ones in the free case. By this wall can be screened by the layer. Therefore, the reflection takes place as the one from a soft boundary $\langle\mathrm{Fig} .3, \mathrm{c}\rangle$. Such effect was observed for the intensities of incident pulse less than $2 \mathrm{MPa}$ and the gradient of void fraction more than $0.1 \mathrm{l} / \mathrm{cm}$. Nevertheless, in this case wall affects the behaviour of oscillations, following behing the main wave of rarefaction (compare $F i g .3, a$ and $c$ ). As amplitude of incident signal increases, reflection factor decreases. As void fraction and its spatial gradient decrease, its absolute value decreases and dependence on amplitude becomes weaker. At further decrease of void fraction the reflection factor will be determined already by rigidness of the wall.

The calculation of the reflected signal structure was carried out. after the model, which essence and criteria of the applicability were discussed in detail in [1]. The model takes into account essential change of the bubble volume and nonlinear dynamics of. the bubbles in the wave field as well as specific distribution of void fraction and the bubble sizes within the layer. In the case of a free layer the calculations allowed to estimate the both of amplitude and form of the firsts oscillations correctly. ( $F$ ig. $4, a$ and $b$ ) and also to be convinced of that the presence of the wall do not change the shape of the negative phase of reflected pulse at the moderate intensities of the incident signal as well as at the sufficiently large gradients of void fraction (Fig. 4, c). As gradient of void fraction increases, front of reflected pulse becomes steeper. This effect is well fitted by our calculations too. The modelling, ignoring the local parameters of the layer do not allow to 
describe the experimental data quantitatively ( $F$ ig. 4 , a and b, curve 2).

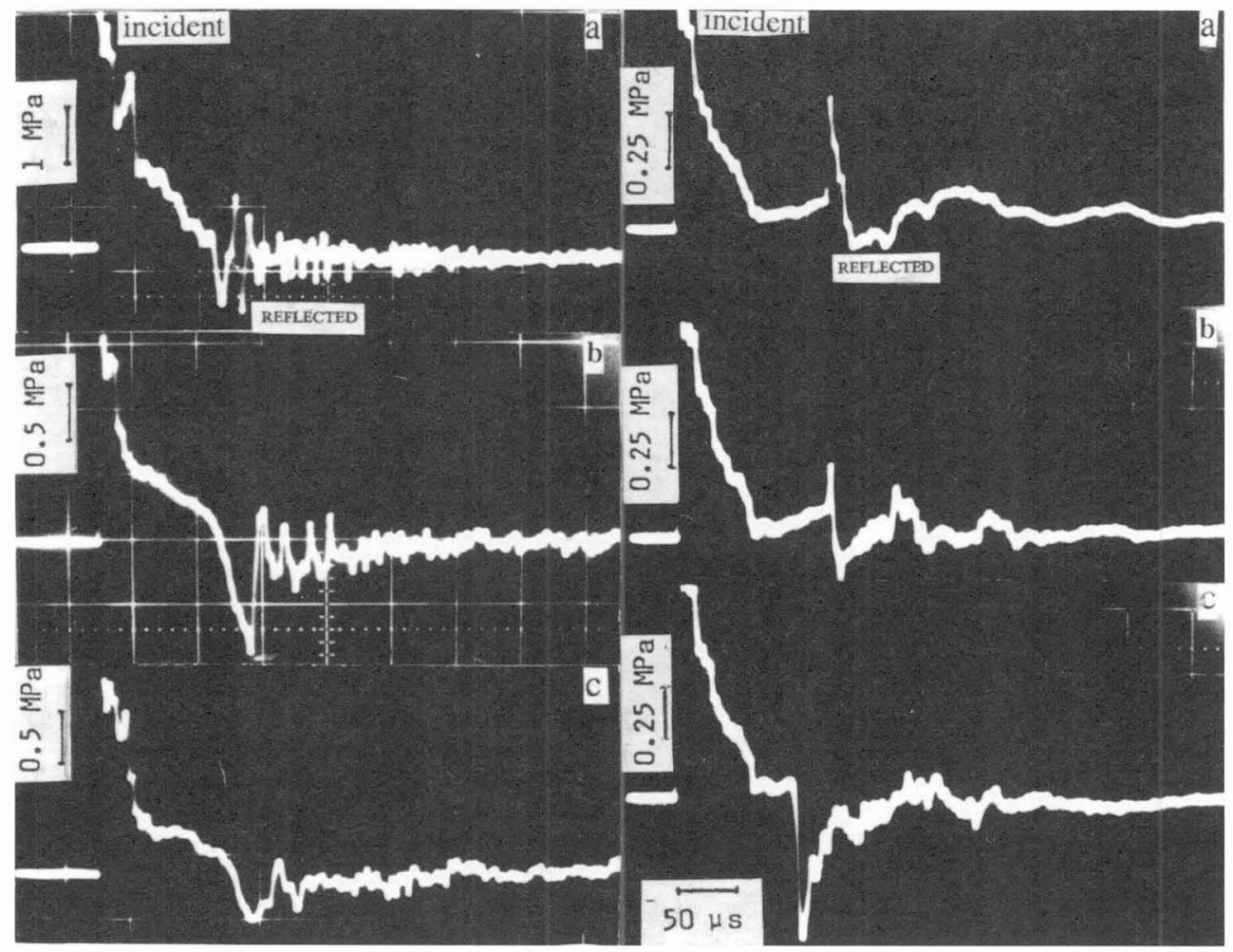

Fig. 1

Reflection from the free layer Thickness of the layer, maximum of void fraction in it, spatial gradient at the layer origin are respectively,

a,b) $24 \mathrm{~cm}, 0.29,0.0211 / \mathrm{cm}$;

c) $16 \mathrm{~cm}, 0.013,0.0021 / \mathrm{cm}$. a) layer without bubbles;

b) $1.2 \mathrm{~cm}, 0.012,0.0241 / \mathrm{cm}$;

c) $2.4 \mathrm{~cm}, 0.29,0.11 / \mathrm{cm}$.

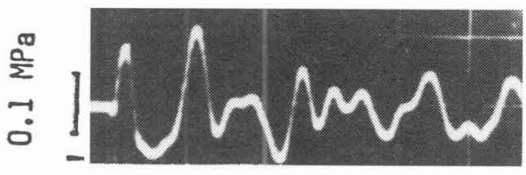

10 Hs

Fig. 2. Wave structure inside the layer at a distance of $16 \mathrm{~cm}$. Parameters of the layer are the same as ones cited in caption Fig. 1, c. Amplitude of the incident pulse is $0.7 \mathrm{MPa}$. 

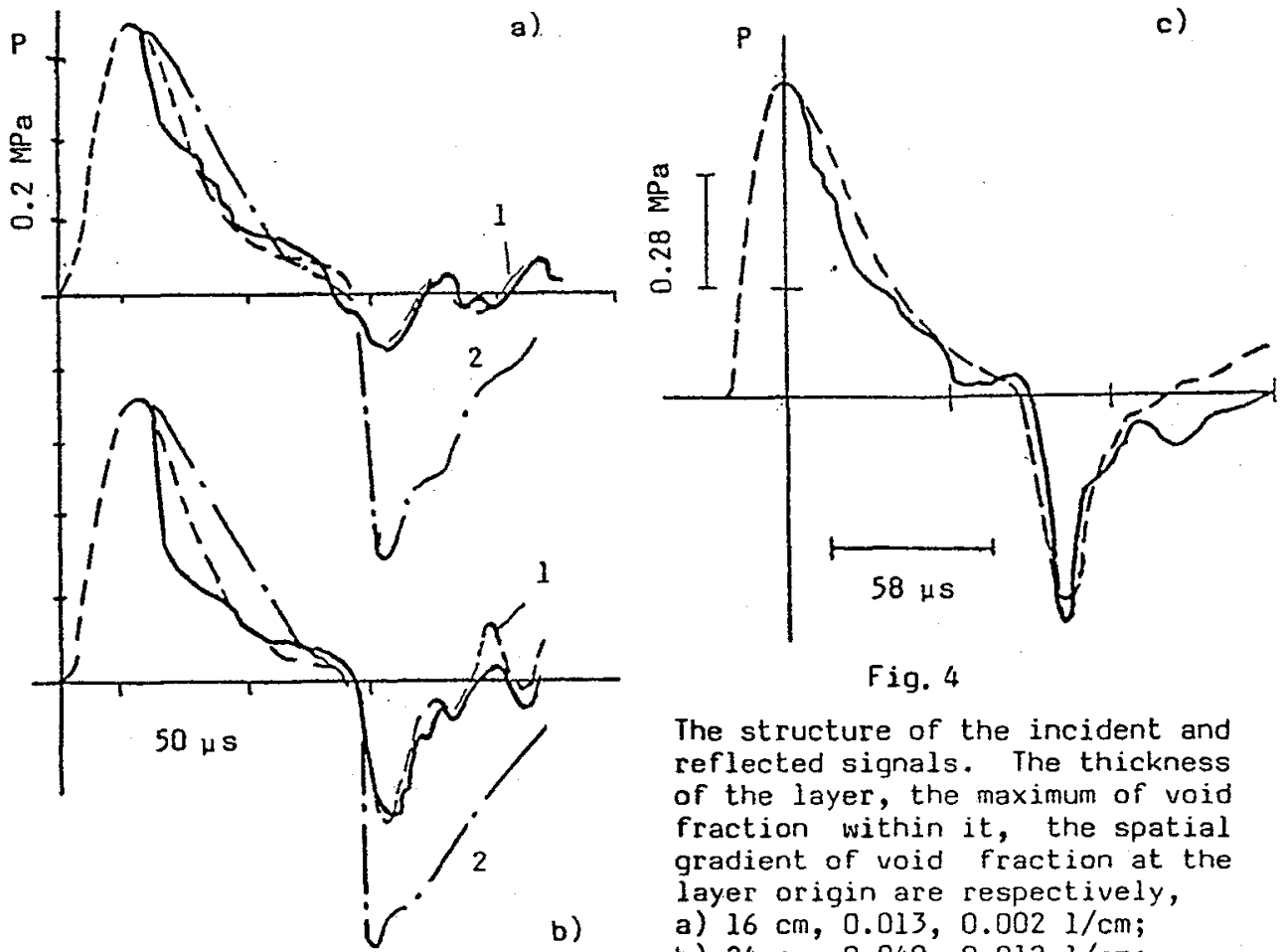

Fig. 4

The structure of the incident and reflected signals. The thickness of the layer, the maximum of void fraction within it, the spatial gradient of void fraction at the layer origin are respectively,

a) $16 \mathrm{~cm}, 0.013,0.0021 / \mathrm{cm}$;

b) $24 \mathrm{~cm}, 0.049,0.0121 / \mathrm{cm}$;

c) $2.4 \mathrm{~cm}, 0.29,0.11 / \mathrm{cm}$;

a,b) free layer: solid line corresponds to experiment, 1 - careful calculations; 2 - calculations, 'ignoring the distribution of the void fraction and the bubble sizes within the layer;

c) near-wall layer: solid line corresponds to experiment, dotted line corresponds to calculations, ignoring the presence of the wall.

3. Conclusion

Analysis of the experimental data and given calculations show that reflection of strong pressure pulses from the bubble layers in water is the process of dynamic interaction of incident pulse with nonlinearly pulsating bubbles of the layer. As gradient of void fraction in the layer is greater and the incident pulse amplitude is smaller, the thiner layer forms the reflected signal with less dispersive and nonlinear distortions. Otherwise, the shape of reflected signal becomes sensitive to the internal structure of the layer. For near-wall layers this leads to the fact that structure of reflected wave is determined by complicated interactions of the secondary waves re-emitted and scattered by the bubbles as well as the perturbations, generated by the wall itself. To make calculationcarefully it is necessary to consider the specific distribution of void fraction and sizes of the bubles within the layer as well as the essentially nonlinear dynamics of bubbles in it.

References

[1] Derzho O.G., Malykh N.V.: Archives of mechanics, 42, 4-5, 463 (1990) 